\title{
Self-Efficacy and Shot Success of Basketball Players
}

\author{
Raymund Jason P. Santua \\ Santua Training and Review Center, Iloilo City, Philippines
}

\begin{tabular}{l} 
Article history \\
Submitted: 31 March 2020 \\
Revised: 17 June 2020 \\
Accepted: 13 November 2020 \\
\hline Keywords \\
Psychology \\
Self-Efficacy \\
Shot Success \\
Basketball Players \\
Descriptive-Correlation \\
Iloilo City
\end{tabular}

Introduction. In the Philippines, basketball is a popular sport, and there are local, provincial, and regional and national competitions (Antolihao, 2010). From urban and rural areas, both public and private institutions, organizations, sectors, different schools province, city, municipality or towns, barangays and every corner of the street or block, Filipinos play basketball even in a small area that can make a small court or half-court and a basketball ring or sometimes a basketball ring without a board (De la Cruz, 2016). A tale or a myth attests to the powerful influence of Filipinos' sport and a keen interest in basketball and its existence in their archipelagic geography, despite the sport being designed or tailor-made for tall people (Dumaraos, 2016). There are varsity players in colleges who are scholars because of their ability to play this game. The sports career of basketball players goes a long way even when they have graduated from school. They may become professional and paid basketball players later (Sugai, 2010). However, being an expert basketball player requires much practice. Basketball players may be professionally trained or may have started as a backyard player or may have no professional training. There are backyard players who have very high accuracy and precision in shooting, which are part of their genetic characteristics (Perine, 2016). Nevertheless, these genetic characteristics may be enhanced by experience. On the other hand, Ortega, Olmedilla, de Baranda, and Gomez (2009) found that basketball players with high self-efficacy have higher performance or shot success. The success of shooting the ball may depend on the confidence that a person had had when he was shooting. The more confident he has been, the better his chance of being precise in the shooting. This is selfefficacy, confidence, and the effectiveness of achieving success in one's aim (Perlman, 2018). Hence, the study aimed to describe, compare, and correlate self-efficacy and shot success of basketball players of the Iloilo City Mayor's Cup.

Methods. This study utilized a descriptive, comparative, and correlational research design. The respondents of this study were the 240 basketball players in the Mayor's Cup of Iloilo City. They were chosen using purposive sampling, considering that they have played in the 2018 Iloilo Mayor's Cup. A self-made questionnaire adopted from the General Self-Efficacy (GSE) Scale of Schwarzer and Jerusalem (1995) and a checklist for shot success were used to gather data. The data gathered were subjected to descriptive and inferential statistics using Mean, Standard Deviation, frequency count, percentage distribution, t-test, Analysis of Variance (ANOVA), and Pearson r.

Results. The general self-efficacy of the players was generally high. The perceived shot success of the players was also generally high. When grouped according to age and number of hours watching basketball per week, the players showed a significant difference in their general self-efficacy. Those aging above 30 and watched basketball above 20 hours per week had significantly the highest selfefficacy. Whether formally trained or not, they did not significantly affect self-efficacy. Those with ages of at least 27 had significantly highest perceived shot success. The number of hours watching basketball and whether formally trained or not showed no significant difference in the perceived shot success. A significant correlation was found between self-efficacy and perceived shot success.

Conclusion. Based on the findings, this study concludes that the general self-efficacy of the players is high. The perceived shot success is also high. The higher the general self-efficacy, the higher is the perceived shot success. A support program for augmenting the general self-efficacy of the basketball players is recommended for the trainers of basketball players. 
Practical Value of the Paper. This study significantly contributes to the dearth, if not absence, of local studies correlating self-efficacy and shot success of basketball players. The findings of the study may serve as baseline data in designing a self-efficacy and physical fitness program for basketball players.

\section{References}

Achterkamp, R., Hermens, H. J., \& Vollenbroek-Hutten, M. M. (2015). The influence of success experience on selfefficacy when providing feedback through technology. Computers in Human Behavior, 52, 419-423.

Antolihao, L. (2010). Rooting for the Underdog Spectatorship and Subalternity in Philippine Basketball. Philippine studies, 449-480.

Ayazi, M., Divkan, B., Shahbazi, M., \& Afsha, L. (2013). Predicted of fear of success from self-efficacy among professional athletes (swimming, gymnastic \& track and field): Islamic azad university Roudehen branch. European Journal of Experimental Biology, 3(3), 328-332.

De la Cruz, Esther. (June 19, 2017). Why the Philippines is obsessed with Basketball. Retrieved from https:// theculturetrip.com/asia/philippines/articles/why-is-the-philippines-obsessed-with-basketball/

Dumaraos, G. (2016). Basketball in the Philippines. Retrieved from https://primer.com.ph/tips-guides/2016/03/29/basketball-in-the-philippines/

Li, L., Simiyu, W. W., Liao, T., \& Feng, Y. (2017). Selected demographic characteristics of male basketball players: the case of China and the USA. Journal of Physical Education and Sport, 17(4), 2678-2684.

Ortega, E., Olmedilla, A., de Baranda, P. S., \& Gómez, M. Á. (2009). Relationship between the level of self-efficacy, performance indicators, and participation in youth basketball. Revista de Psicologia del deporte, 18(3), 337 342.

Padulo, J., Nikolaidis, P. T., Cular, D., Dello Iacono, A., Vando, S., Galasso, M., ... \& Ardigò, L. P. (2018). The effect of heart rate on jump-shot accuracy of adolescent basketball players. Frontiers in physiology, 9, 1065.

Sugai, N. (2010). An Examination of the 19 Year Old Age Minimum and the Choice between On-The-Job Training and Schooling for NBA Prospects. Retrieved from https://www.amherst.edu/media/view/329619/original/ Sugai-EffectEarlyEntrytoNBA.pdf

Tladi, L. S. (2017). Perceived ability and success: which self-efficacy measures matter? A distance learning perspective. Open Learning: The Journal of Open, Distance and e-Learning, 32(3), 243-261.

\section{Correspondence:}

Raymund Jason P. Santua [raymundsantua@yahoo.com.ph] 